\title{
KONSEP PENGAMANAN PESAN DENGAN TEKNIK ENKRIPSI END-TO-END PADA WHATSAPP MESSENGER
}

\author{
${ }^{1}$ Jamaluddin Jamaluddin, ${ }^{2}$ Roni J. Simamora, ${ }^{3}$ Karyawati Sitepu \\ ${ }^{1,2,3}$ Dosen Program Studi D-III Manajemen Informatika \\ Universitas Methodist Indonesia \\ 1james_coleps@yahoo.com,
}

\begin{abstract}
Abstrak
Perkembangan teknologi telekomunikasi yang cepat telah memberikan banyak manfaat. Dengan adanya teknologi ini komunikasi jarak jauh tidak lagi menjadi penghalang. Salah satu teknologi yang sering digunakan adalah pengiriman pesan singkat (SMS). Pengiriman pesan singkat (SMS) merupakan hal yang sudah sering dilakukan oleh semua orang untuk berkomunikasi. Tetapi pesan yang dikirimkan tidak langsung sampai kepada penerima tetapi terlebih dahulu singgah di jaringan SMS center penyedia layanan. Dengan penerapan teknik enkripsi end-to-end pada WhatsApp Messenger maka hanya pengirim dan penerima sajalah yang hanya dapat membuka dan membaca pesan asli yang dikirimkan walaupun pesan terlebih dahulu singgah pada server penyedia layanan.
\end{abstract}

Kata Kunci : Pesan, WhatApp Messenger, Enkripsi, End-to-end.

\section{Pendahuluan}

Perkembangan teknologi informasi dan komunikasi khususnya layanan pengiriman pesan yang memanfaatkan jaringan data internet sudah dimanfaatkan hampir oleh semua lapisan masyarakat seperti aplikasi WhatsApp Messenger (WA), Blackberry Messenger (BBM), Kakao Talk, LINE, WeChat dan aplikasi pengiriman pesan yang memanfaatkan jaringan data lainnya. Permasalahan kemudian muncul apakah dengan menggunakan aplikasi pengiriman pesan yang "gratis" tersebut pesan kita aman dari penyadapan.

Pengiriman pesan tersebut membutuhkan pengamanan yang berupa penyandian pesan sehingga pesan yang dikirimkan merupakan pesan yang telah disandikan. Penerapan sistem keamanan mutlak dibutuhkan untuk menjamin privasi pelanggan yang menggunakan aplikasi tersebut. Pada jurnal ini penulis akan membahas tentang pengamanan pesan yang diterapkan oleh WhatApp Messenger (WA) dengan menggunakan teknik enkripsi end-toend.

\section{Landasan Teori \\ 2.1 Kriptografi}

Kriptografi (Cryptography) berasal dari bahasa Yunani, terdiri dari dua suku kata yaitu kripto dan graphia. Kripto artinya menyembunyikan, sedangkan graphia artinya tulisan. Jadi, kriptografi adalah ilmu yang mempelajari teknik-teknik matematika yang berhubungan dengan aspek keamanan informasi, seperti kerahasiaan data, keabsahan data, integritas data, serta autentikasi data. Tetapi tidak semua aspek keamanan informasi dapat diselesaikan dengan kriptografi. Kriptorafi dapat pula diartikan sebagai ilmu atau seni untuk menjaga keamanan pesan. Ketika suatu pesan dikirim dari suatu tempat ke tempat lain, isi pesan tersebut. Untuk menjaga pesan, maka pesan tersebut dapat 
diubah menjadi suatu kode yang tidak dapat dimengerti oleh pihak lain.

Ada empat tujuan mendasar dari kriptografi yang juga merupakan aspek keamanan informasi yaitu:

1. Privacy/Confidentiality: yaitu usaha menjaga informasi dari orang yang tidak berhak mengakses (mengaransi bahwa data pribadi tetap pribadi).

2. Integrity: yaitu usaha untuk menjaga data atau sistem tidak diubah oleh yang tidak berhak.

3. Authentication: yaitu usaha atau metoda untuk mengetahui keaslian dari informasi, misalnya apakah informasi yang dikirim dibuka oleh orang yang benar (asli) atau layanan dari server yang diberikan benar berasal dari server yang dimaksud.

4. Availability: berhubungan dengan ketersediaan sistem dan data (informasi) ketika dibutuhkan.

Dalam menjaga kerahasiaan data, kriptografi mentransformasikan informasi asli atau dikenal dengan sebutan (plaintext) ke dalam bentuk informasi yang di acak/di enkripsi (ciphertext) yang tidak dikenali. Ciphertext inilah yang kemudian dikirimkan oleh pengirim (sender) kepada penerima (receiver). Setelah sampai di penerima, ciphertext tersebut ditransformasikan kembali dalam bentuk plaintext agar dapat dikenali.

Suatu pesan yang tidak disandikan disebut sebagai plaintext ataupun dapat disebut juga sebagai cleartext. Proses transformasi dari plaintext ke ciphertext dikenal dengan proses enkripsi. Sedangkan proses transformasi dari ciphertext ke plaintext dikenal dengan proses dekripsi. Kedua proses tersebut dilakukan dengan menggunakan algoritma tertentu yang dikenal dengan kunci.

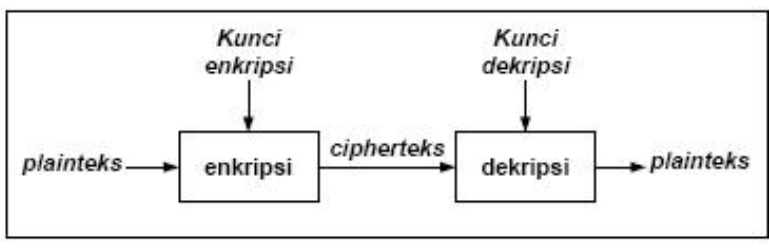

Gambar 1. Proses Enkripsi dan Dekripsi pada Kriptografi

\subsection{Enkripsi End-to-end}

Teknik enkripsi end-to-end merupakan teknik pengenkripsian pesan yang dilakukan pada saat pesan akan dikirimkan dan kembali di dekripsikan pada saat pesan sampai di tujuan (penerima). Dengan teknik enkripsi end-to-end, paket dienkripsi sekali pada sumber enkripsi asli dan kemudian didekripsi hanya pada tujuan akhir dekripsi.

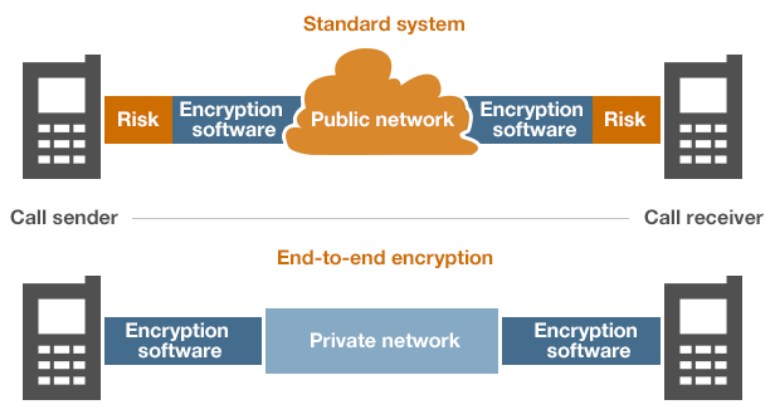

Gambar 2. Perbandingan Sistem Pengiriman Pesan Standard dengan Sistem Enkripsi Endto-end

Keuntungan dari end-to-end enkripsi adalah kecepatan dan keamanan secara keseluruhan.

\subsection{SMS (Short Messages Servives}

SMS adalah sebuah teknologi yang menyediakan layanan penerimaan dan pengiriman pesan singkat antara perangkat mobile. SMS pertama kali dikenalkan di Eropa sekitar tahun 1992, yang pertama kali terintegrasi dalam GSM (Global System for Mobile, Communications) yang kemudian berkembang dalam CDMA dan TDMA. Sebuah SMS memiliki batasan karakter yang dapat dikirimkan, 160 karakter jika pengkodean karakter 7-bit yang digunakan dan 
70 karakter jika 16-bit Unicode UCS2 (2-byte Universal Character Set) pengkodean karakter yang digunakan. SMS dapat dikirimkan ke perangkat stasiun seluler digital lainnya hanya dalam beberapa detik selama berada pada jangkauan pelayanan GSM.

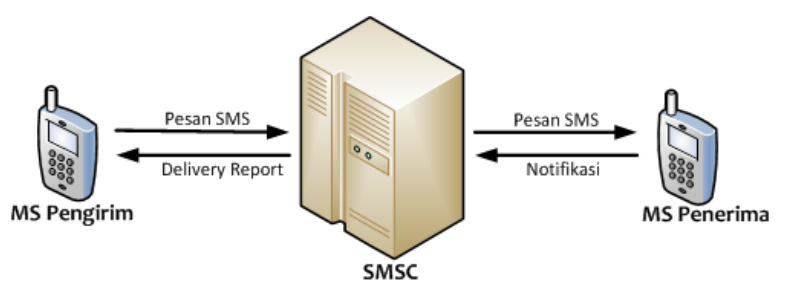

Gambar 3. Skema Pengiriman SMS

SMS dapat memberikan pelayanan apabila pesan yang dikirim tidak sampai ke penerima karena perangkat penerima tidak aktif maupun perangkat penerima diluar jangkauan layanan GSM. Sistem Operasi Mobile Android adalah sistem operasi untuk telepon seluler yang berbasis Linux yang mencakup sistem operasi, middleware, dan aplikasi. Android menyediakan platform terbuka bagi para pengembang untuk menciptakan aplikasi sendiri untuk digunakan oleh bermacam peranti mobile.

\subsection{WhatsApp Messager}

WhatsApp Messenger adalah aplikasi pesan seluler lintas platform yang memungkinkan Anda untuk bertukar pesan tanpa harus membayar SMS.

Aplikasi WhatsApp merupakan aplikasi besutan WhatsApp Inc yang didirkan oleh Brian Acton dan Jan Koum pada tahun 2009. Kedua orang tersebut sebenarnya juga merupakan mantan pekerja senior di Yahoo. Ide awal WhatsApp muncul dari Jan Koum yang mempunyai ide untuk membuat satu aplikasi yang dapat membroadcast status meski orang tersebut dalam kondisi yang sulit untuk dihubungi. Saat itu ia mengajak Acton untuk bekerjasama. Pada awalnya aplikasi ini hanya menarik sebagian kecil orang. Namun setelah menambahkan fitur messaging aplikasi ini menjadi semakin populer.

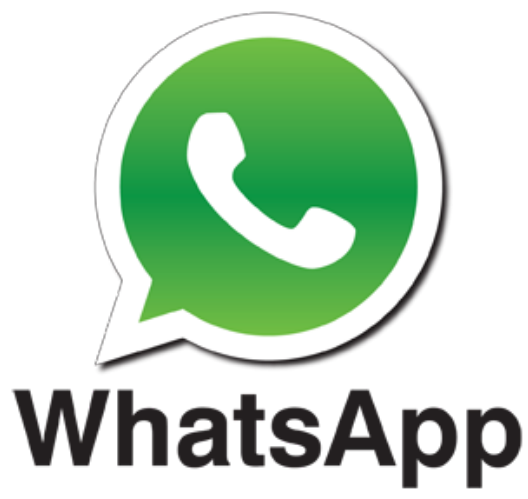

Gambar 4. Logo WhatsApp

Saat ini WhatsApp Messenger telah tersedia untuk iPhone, BlackBerry, Windows Phone, dan smartphone berbasis Android. dan benar, semua ponsel ini bisa berkirim pesan satu sama lain! Ini dimungkinkan karena WhatsApp Messenger memakai paket data internet yang Anda pakai untuk mengirim email dan menjelajahi internet, sehingga mengirim pesan dan tetap berhubungan dengan teman-teman tidak akan dikenakan biaya.

Selain fitur dasar berkirim pesan, pengguna WhatsApp dapat membuat grup, saling berkirim gambar, pesan video dan audio dalam jumlah tidak terbatas.

\section{Skema Pengamanan Pesan dengan Teknik Enkripsi End to End pada WhatsApp Messenger \\ WhatsApp Messeger mulai tanggal 6 April} 2016 resmi merilis mode keamanan dengan menggunakan teknik enkripsi End-to-End. Mode ini membuat setiap pesan yang dikirim terenkripsi secara aman dan hanya bisa dibuka oleh pengirim dan penerima pesan tersebut. Dengan menggunakan teknik ini seluruh pesan yang dikirimkan dan diterima oleh pengguna 
WhatsApp kini tidak bisa disadap oleh pihak ketiga. Pesan tersebut hanya bisa dibaca oleh penerima yang dituju, termasuk layanan telepon, gambar, video, dan pesan suara.

Teknik enkripsi end-to-end merupakan sebuah sistem dimana proses enkripsi terjadi pada saat pesan dikirimkan dan hanya terdekripsi pada saat pesan sampai kepada penerima. Bahkan pihak WhatsApp sendiri akan kesulitan untuk menyerahkan rekaman data penggunanya ke pihak yang berwajib, karena sistem enkripsi end-to-end dirancang agar tidak bisa dibobol (kriptanalisis) oleh pembuatnya sekalipun.

Dengan sistem enkripsi end-to-end ini pengguna WhatsApp tentunya tidak perlu mengkhawatirkan privasi mereka. Pihak pemerintah ataupun kepolisian juga akan sulit untuk memata-matain percakapan yang dilakukan oleh pengguna karena semua pesan dan data yang dikirimkan merupakan kumpulan kode yang telah terenkripsi dan tidak dapat dimengerti. Kode tersebut hanya dapat dibaca pada perangkat penerima pesannya, sehingga pihak ketiga secara otomatis tidak dapat bisa menyadap percakapan di WhatsApp.

Sebagai ilustrasi pengirim pesan di WhatsApp mengirimkan pesan “Apa Kabar?”, pada saat pesan dikirimkan maka pesan tersebut akan dienkripsi secara otomatis menjadi "9XB80FFAH". Kode tersebut sangat tidak akan dimengerti oleh pihak ketiga yang menyadapnya. Tetapi sesampainya pesan ke penerima maka secara otomatis kode "9XB80FFAH" akan kembali didekripsikan menjadi pesan semula “Apa Kabar?”. Dengan menggunakan teknik enkripsi end-to-end maka segi privasi pengguna aplikasi WhatsApp lebih terjamin.

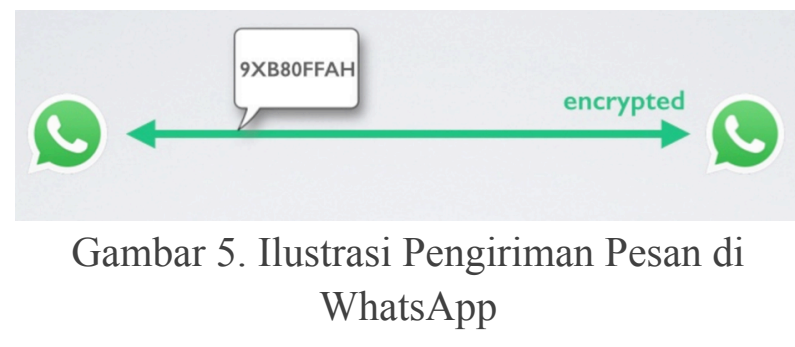

Menurut pakar Teknologi Onno W. Purbo, dengan menggunakan fitur enkripsi end-to-end di WhatsApp akan menyulitkan penyidik untuk melakukan penyadapan. Sehingga teknik enkripsi end-to-end ini penting untuk melindungi privasi seseorang.

Namun disaat yang sama, fitur keamanan tingkat tinggi ini juga dapat dimanfaatkan oleh pelaku kejahatan, termasuk teroris, koruptor dan lain-lain. Salah satu praktisi kemananan internet Indonesia mengatakan fitur enkripsi end-to-end di WhatsApp sangat menguntungkan bagi penjahat dalam melakukan setiap perencanaan maupun perwujudan dari perencanaan mereka.

\section{Kesimpulan}

Berdasarkan uraian diatas, maka penulis dapat menarik kesimpulan sebagai berikut:

1. Penyediaan Fitur keamanan dengan teknik enkripsi end-to-end pada aplikasi WhatsApp meningkatkan privasi pengguna dalam berkomunikasi dengan orang lain.

2. Fitur keamanan dengan enkripsi end-to-end pada aplikasi WhatsApp harus dimanfaatkan untuk hal-hal yang positif karena fitur ini juga dapat dimanfaatkan untuk melakukan kejahatan. 


\section{Daftar Pustaka}

Anggraeni, L., 2016. Praktisi Kemananan: Enkripsi End-to-End WhatsApp Menguntungkan Penjahat. News.MetroTVNews.com. 6 April 2016 (diakses 12 April 2016)

Buchmann, J.A. 2004. Introduction to Cryptography. $2^{\text {nd }}$ ed. New York. Springer.

Dahwilani, D.M., 2016. Lindungi Data Pengguna WhatsApp Gunakan Enkripsi Terbaru. SindoNews.com. 6 April 2016 (diakses 11 April 2016)

Kurnia, D., 2014. Pengamanan Pesan SMS dengan Menggunakan Algoritma Caesar Cipher dan RSA. Prosiding Seminar Nasional Teknologi Informasi dan Komunikasi (SNASTIKOM) 2014. Page 9-15 Information Security.

Mollin, R.A. 2007. An Introduction to Cryptography. $2^{\text {nd }}$ ed. New York. Chapman \& Hall / CRC.

Ngazis, A.N., 2016. WhatsApp Resmi Dilindungi Enkripsi. News.Viva.co.id. 6 April 2016 (diakses 11 April 2016)

Satriawan, I W.D., Sasmita, I G.M.A., Bayupati, I P.A., 2014. Aplikasi Enkripsi SMS dengan Metode RSA pada Smartphone Berbasis Android. Menara Penelitian Akademika Teknologi Informasi (MERPATI) Vol. 2 No. 2. Hal. 127-134.

Saxena, N. \& Payal, A., 2011. Enhancing Security System of Short Message Service for MCommerce in GSM. International Journal of Computer Science \& Engineering Technology (IJCSET) Vol. 2 No. 4. Page 126-133.

Stalling, W. 2005. Cryptography and Network Security Principles and Practices, $4^{\text {th }}$ edition, Prentice Hall.

Utomo, R.M., 2016. Onno W. Purbo: Enkripsi WhatsApp Buat Penyidik Sulit Menyadap. News.MetroTVNews.com. 6 April 2016 (diakses 11 April 2016)
Wiharto, Y., 2011. Sistem Informasi Akademik Berbasis SMS Gateway. Jurnal Teknologi dan Informatika (Teknomatika) Vol. 1 No. 1. Hal. 1-28. 